\title{
Dry electrical discharge dressing and truing of diamond grinding wheel V-tip for micro-grinding
}

\author{
Y. J. Lu ${ }^{a_{*}}$, L. J. Li $i^{b}$, J. Xie ${ }^{c}$, C. L. Zhou ${ }^{d}$ and R. B. Guo ${ }^{\mathrm{e}}$ \\ School of Mechanical and Automotive Engineering, South China University of Technology, \\ Guangzhou 510640, China; \\ aluyanjun_szu@163.com, 'liliejun@scut.edu.cn, cjinxie@scut.edu.cn, \\ dzhouchaolan_scut@163.com, 'scutgrb1992@163.com
}

\begin{abstract}
The dry electrical discharge dressing and truing technology was proposed to realize the high efficient and precise truing of diamond grinding wheel in this paper. Firstly, the V-shape tip of diamond grinding wheel was formed using dry electro-contact discharge (ECD) truing along setting crossed V-shape interpolation path. Secondly, the influence of different pulse discharge parameters on V-tip angle and V-tip radius was investigated, respectively. Finally, the trued V-tip diamond wheel was employed to fabricate micro-groove and micro-pyramid array structures on the surfaces of two hard and brittle materials by micro-grinding machining. The results indicated that the optimal pulse discharge parameters were open-circuit voltage $E$ of $5 \mathrm{~V}$, pulse frequency $f$ of $4000 \mathrm{~Hz}$ and duty cycle $d_{c}$ of $50 \%$. The least V-tip angle error and radius of trued SD600 V-tip diamond grinding wheel was $1.1^{\circ}$ and $33 \mu \mathrm{m}$, respectively. The micro-groove and micro-pyramid structures with regular shape and smooth surface can was effectively machined on the surfaces of difficult-to-cut materials.
\end{abstract}

Keywords: electrical discharge, dressing and truing, diamond grinding wheel, micro-grinding.

\section{Introduction}

The regular micro array structure at micron scale was machined on the surface of hard and brittle materials, which may produce new functional performance [1]. However, the micro-structured surface machining of difficult-to-machine materials was very difficult. It is known that precision grinding based on diamond grinding wheel is the most effective micro machining method [2].

However, the dressing and truing of diamond grinding wheel is the critical problem. The truing efficiency and precision have been technology bottleneck in industrialization. It had been confirmed that the dry electro-contact discharge (ECD) dressing and truing could vastly improve the truing efficiency [3]. Therefore, the dry ECD truing was developed to realize high efficient and precise V-tip truing of diamond grinding wheel.

The shape accuracy of machined micro-structures on material surface depends on form accuracy of diamond grinding wheel micro tip [4]. Therefore, the investigation on V-tip truing accuracy is very significant. The V-tip angle and radius were analyzed under different pulse discharge parameters to obtain the highest truing accuracy. In order to test the effectiveness of V-tip truing, two hard and brittle materials were used to conduct the micro-grinding experiments. The ground surface topographies were observed to verify the grinding performance of trued V-tip diamond grinding wheel.

\section{Experimental setup of dry ECD}

Fig. 1 shows the dry electro-contact discharge (ECD) truing and micro-grinding of V-tip diamond grinding wheel. The pulse power supply was connected between hybrid electrode ( $\mathrm{Cu}$ and $\mathrm{SiC}$ ) and metal-bonded diamond grinding wheel (see Fig. 1a). The electric spark was produced between metal bond from grinding wheel and rolled $\mathrm{Cu}$ chip when the rotary diamond wheel cut the conductive electrode. The diamond grinding wheel was driven along setting V-shape truing path. Gradually, the V-tip profile of diamond wheel was formed. The detail ECD truing conditions of SD600 diamond grinding wheel V-tip were shown in Table 1. The trued V-tip diamond wheel was 
employed to grind microcrystallite glass ceramics and $\mathrm{SiC}$ reinforced $\mathrm{Al}\left(\mathrm{Al} / \mathrm{SiC}_{\mathrm{p}}\right)$ composites. The micro-groove array structures and micro-pyramid array structures were fabricated on those three material surfaces by micro-grinding machining technology, respectively. The micro-grinding photo of trued SD600 V-tip diamond wheel was shown in Fig. 1b. The machined V-groove depth and space was $500 \mu \mathrm{m}$ and $570 \mu \mathrm{m}$, respectively. The detail micro-grinding machining conditions of SD600 diamond grinding wheel were shown in Table 2.
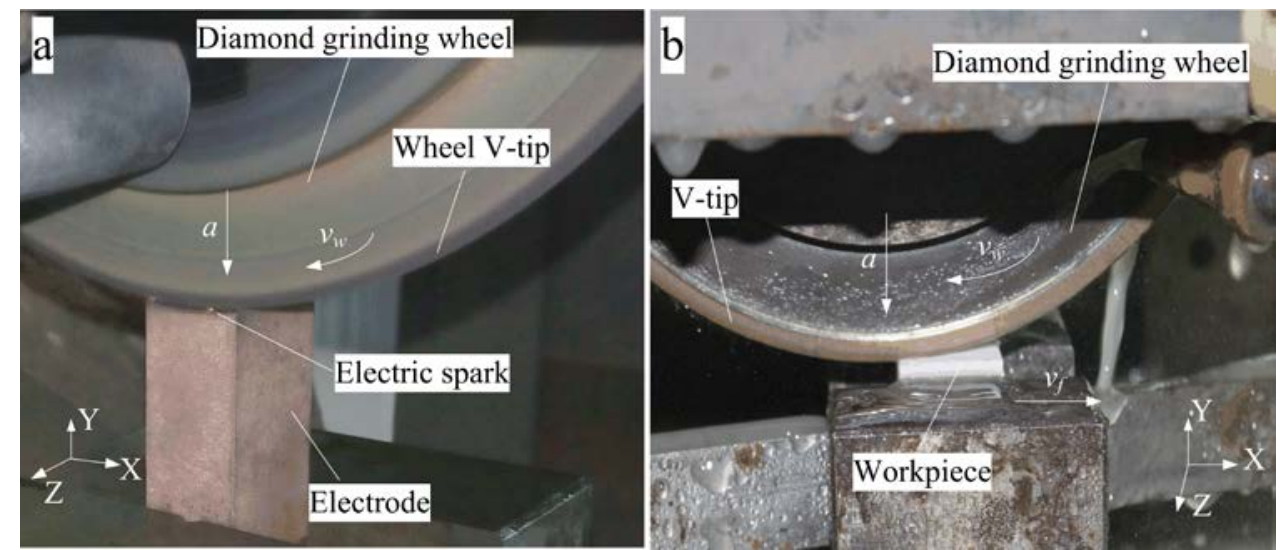

Fig. 1 Dry electro-contact discharge (ECD) truing and micro-grinding of V-tip diamond grinding wheel: (a) photo of V-tip truing and (b) micro-grinding photo of trued V-tip diamond wheel.

Table 1 The ECD truing conditions of SD600 diamond grinding wheel V-tip

\begin{tabular}{ll}
\hline CNC grinder & SMART B818 \\
\hline Diamond grinding wheel & SD600, metal bond, diameter $D=160 \mathrm{~mm}$, width $B=2 \mathrm{~mm}$ \\
\hline Tool truing path & Crossed V-shape interpolation path \\
Truing electrode & Hybrid electrode of Cu and SiC (\#600); Size: $20 \times 50 \times 15 \mathrm{~mm}$ \\
Discharge parameters & $\begin{array}{l}\text { Pulse power supply, open-circuit voltage } E=10 \sim 25 \mathrm{~V} \text {, pulse } \\
\text { frequency } f=1000 \sim 5000 \mathrm{~Hz} \text {, duty cycle } d_{c}=10 \sim 50 \%\end{array}$ \\
& Wheel speed $v_{w}=12.6 \sim 20.9 \mathrm{~m} / \mathrm{s}$, feed speed $v_{f}=200 \sim 500 \mathrm{~mm} / \mathrm{min}$, \\
Truing parameters & depth of cut $a=1 \sim 10 \mu \mathrm{m}$, cumulative feed depth $\Sigma a=0.05 \sim 0.1 \mathrm{~mm}$ \\
Coolant & No
\end{tabular}

Table 2 Micro-grinding machining conditions of SD600 diamond grinding wheel

\begin{tabular}{|c|c|}
\hline CNC grinder & SMART B818 \\
\hline $\begin{array}{l}\text { Diamond } \\
\text { grinding wheel }\end{array}$ & $\begin{array}{l}\text { SD600, metal bond, diameter } D=160 \mathrm{~mm} \text {, width } B=2 \mathrm{~mm} \text {, } \\
\text { wheel speed } v_{w}=25.1 \mathrm{~m} / \mathrm{s}\end{array}$ \\
\hline Tool path & Horizontal reciprocating and crossed interpolation path \\
\hline Rough machining & $\begin{array}{l}\text { Feed speed } v_{\mathrm{f}}=600 \mathrm{~mm} / \mathrm{min} \text {, depth of cut } a=10 \mu \mathrm{m} \text {, cumulative } \\
\text { feed depth } \Sigma a=490 \mu \mathrm{m}\end{array}$ \\
\hline Finish machining & $\begin{array}{l}\text { Feed speed } v_{\mathrm{f}}=300 \mathrm{~mm} / \mathrm{min} \text {, depth of cut } a=2 \mu \mathrm{m} \text {, cumulative } \\
\text { feed depth } \Sigma a=10 \mu \mathrm{m}\end{array}$ \\
\hline Workpieces & $\begin{array}{l}\text { Microcrystallite glass ceramics }(30 \times 15 \mathrm{~mm}) \text {; SiC reinforced } \\
\mathrm{Al}\left(\mathrm{Al} / \mathrm{SiC}_{\mathrm{p}}\right) \text { composites }(10 \times 10 \mathrm{~mm})\end{array}$ \\
\hline Coolant & Water \\
\hline
\end{tabular}

\section{Results and discussions}

Fig. 2 shows the V-shape tip and its grain protrusion topographies of SD600 diamond wheel after dry ECD truing. It is seen that the micro grain protrusion status of V-shape side of diamond wheel was very well. However, micro tip of grinding wheel became dull. This is because the ECD truing time of diamond wheel was too long. There were many protrusive diamond grains on the metal 
bond surface. Therefore, V-shape tip of diamond grinding wheel can be formed by ECD truing. The sharp micro grain cutting edge on the wheel surface was produced along V-shape cutting direction. The trued V-tip diamond wheel can be used in precise micro-grinding machining of hard and brittle materials.
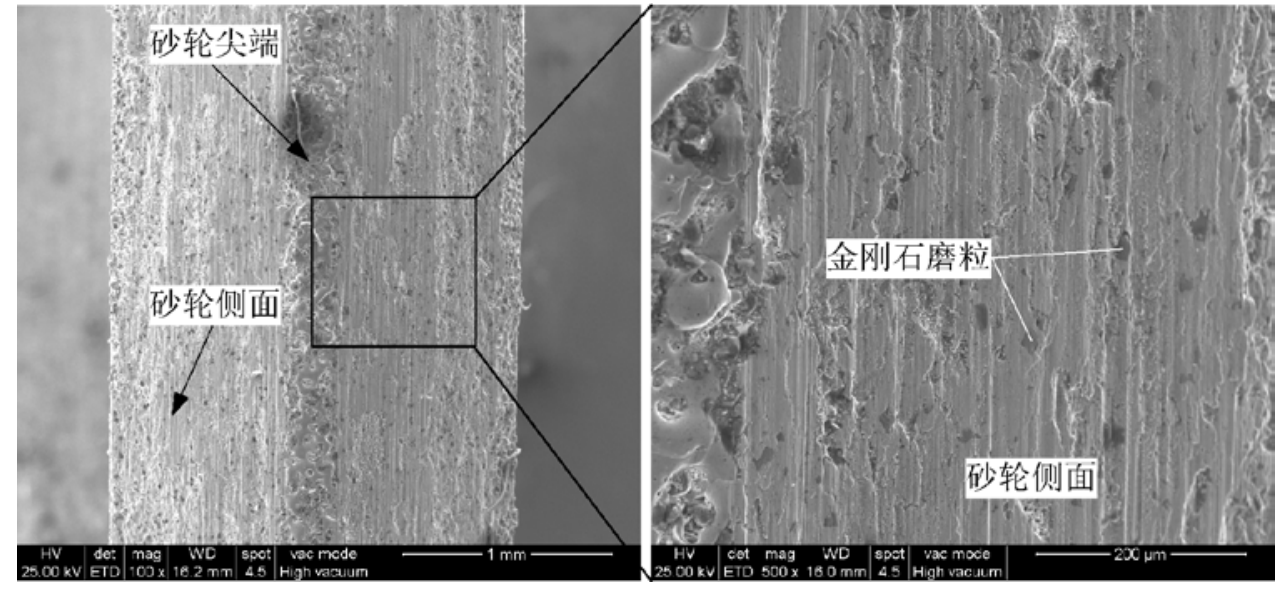

Fig. 2 V-shape tip and its protrusion topographies of SD600 diamond wheel after dry ECD truing.

Fig. 3 shows the influence of different pulse discharge parameters on V-tip angle $\varphi$ of SD600 diamond grinding wheel. When the open-circuit voltage $E$ was $5 \mathrm{~V}$ and $25 \mathrm{~V}$, corresponding V-tip angle $\varphi$ was $88.9^{\circ}$ and $89.4^{\circ}$, respectively. Compared with the setting theoretical truing angle of $90^{\circ}$, the V-tip angle error was only $1.1^{\circ}$ and $0.6^{\circ}$, respectively (see Fig. 3a). The V-tip angle $\varphi$ first gradually decreased, then increased with the increase of pulse frequency $f$ (see Fig. 3b). The reason is that the V-tip truing of diamond wheel was excessive due to the arc discharge. When the pulse frequency $f$ was $4000 \sim 5000 \mathrm{~Hz}$ and duty cycle $d_{c}$ was $50 \%$, the V-tip angle error reached minimum value of $0.6^{\circ}$ (see Fig. 3c).

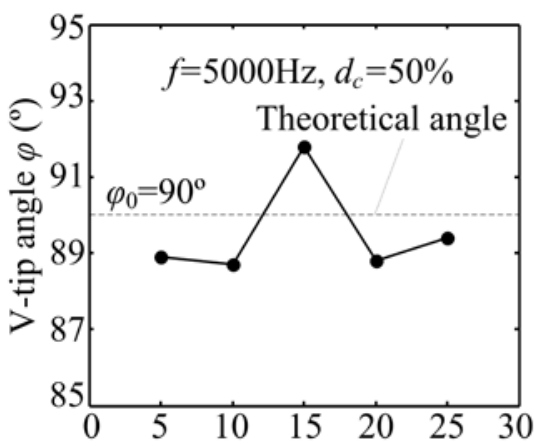

(a) Open-circuit voltage $E(\mathrm{~V})$

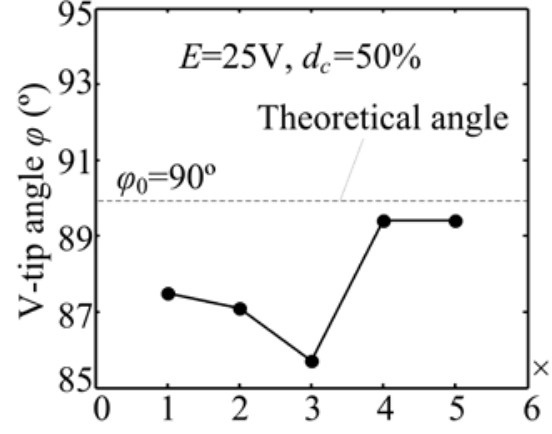

(b) Pulse frequency $f(\mathrm{~Hz})$

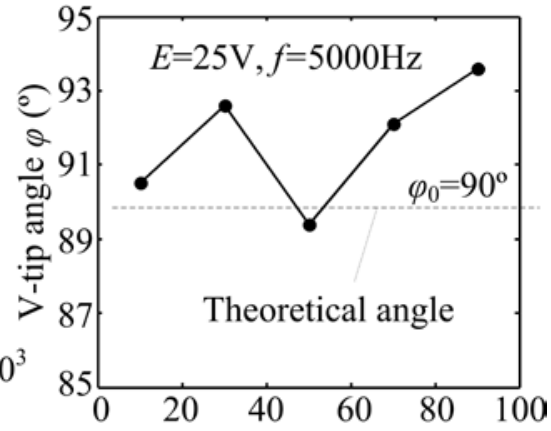

(c) Duty cycle $d_{c}(\%)$

Fig. 3 shows the V-tip angles $\varphi$ of SD600 diamond grinding wheel versus different pulse discharge parameters: (a) open-circuit voltage $E$, (b) pulse frequency $f$ and (c) duty cycle $d_{c}$.

Fig. 4 shows the influence of different pulse discharge parameters on V-tip radius $r_{v}$ of SD600 diamond grinding wheel. The V-tip radius $r_{v}$ increased with the increase of open-circuit voltage $E$ (see Fig. 4a). When the open-circuit voltage $E$ was $5 \mathrm{~V}$, the trued $\mathrm{V}$-tip radius of diamond wheel reached minimum value of $33 \mu \mathrm{m}$. When the pulse frequency $f$ was 4000 and $5000 \mathrm{~Hz}$, corresponding $\mathrm{V}$-tip radius $r_{v}$ was $44 \mu \mathrm{m}$ and $78 \mu \mathrm{m}$, respectively (see Fig. 4b). The V-tip radius $r_{v}$ first gradually decreased, then increased with the increase of duty cycle $d_{c}$ (see Fig. 4c). This is because large and little duty cycle may all cause inhomogenous electrical spark discharge. When the duty cycle $d_{c}$ was $50 \%$, the trued $\mathrm{V}$-tip radius reached minimum value of $78 \mu \mathrm{m}$. As a result, under optimal pulse discharge parameters $\left(E=5 \mathrm{~V}, f=4000 \mathrm{~Hz}\right.$ and $d_{c}=50 \%$ ), the least V-tip angle error and radius of SD600 diamond grinding wheel after ECD truing was $1.1^{\circ}$ and $33 \mu \mathrm{m}$, respectively. 


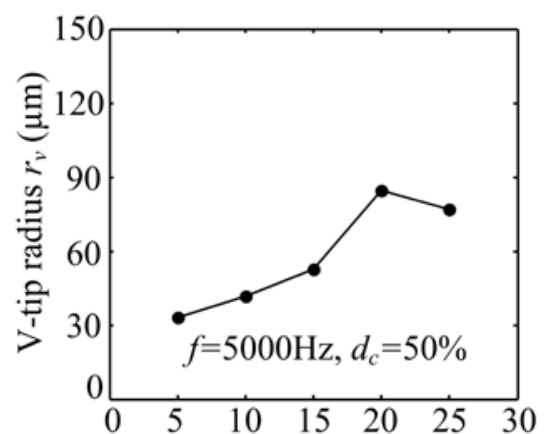

(a) Open-circuit voltage $E(\mathrm{~V})$

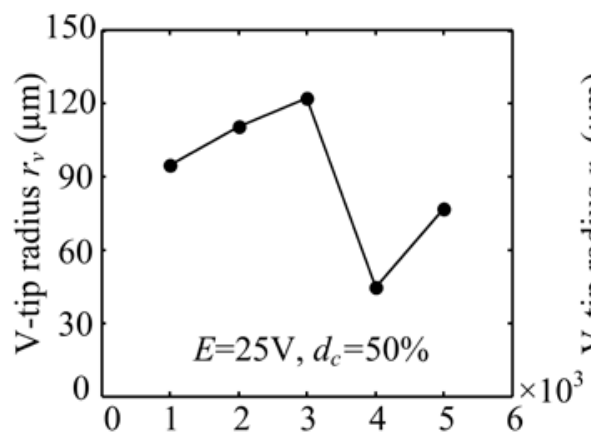

(b) Pulse frequency $f(\mathrm{~Hz})$

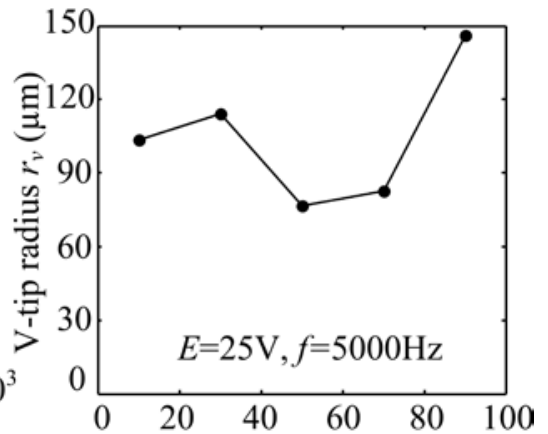

(c) Duty cycle $d_{c}(\%)$

Fig. 4 shows the V-tip radius $r_{v}$ of SD600 diamond grinding wheel versus different pulse discharge parameters: (a) open-circuit voltage $E$, (b) pulse frequency $f$ and (c) duty cycle $d_{c}$.

Fig. 5 displays the ground surface topography of microcrystallite glass ceramics after micro-grinding using trued SD600 V-tip diamond grinding wheel. It is seen that the ground micro-groove and micro-pyramid structured surfaces were very smooth and the edges were not any damaged. Moreover, the V-tip shape of micro-grooves and micro-pyramids spire was also very complete. However, there were many micro holes on the surface of microcrystallite glass ceramics. This is becasue the brittleness of microcrystallite glass ceramics was considerable.

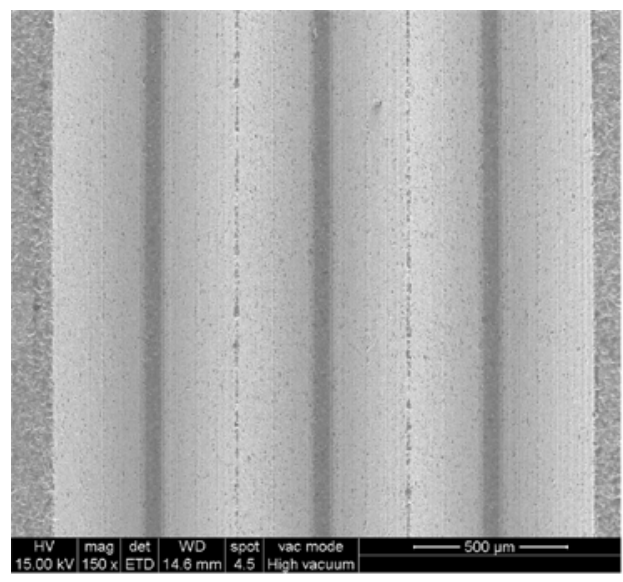

(a) Micro-groove array structure

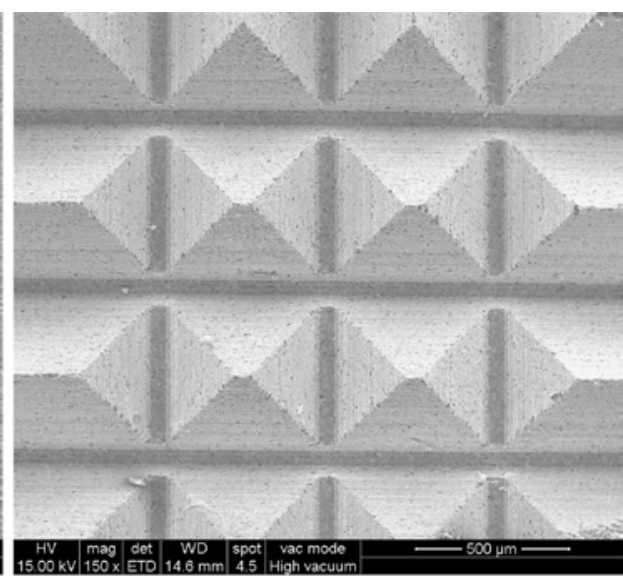

(b) Micro-pyramid array structure

Fig. 5. The ground surface topography of microcrystallite glass ceramics after micro-grinding: (a) micro-groove array structure and (b) micro-pyramid array structure.

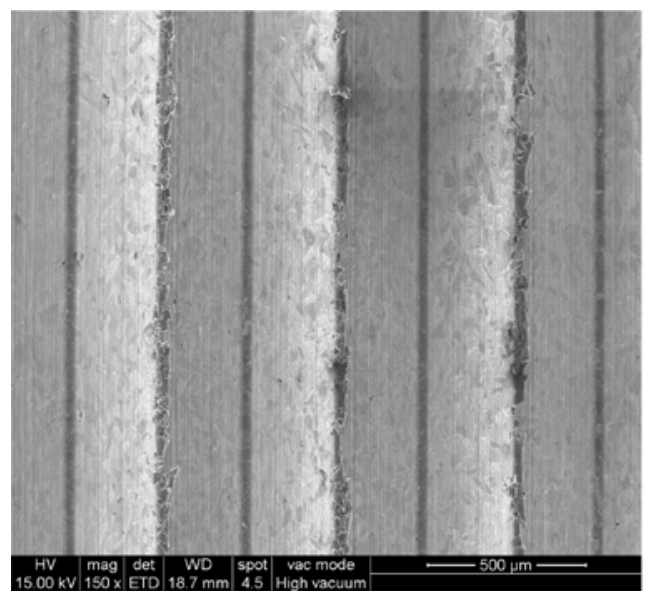

(a) Micro-groove array structure

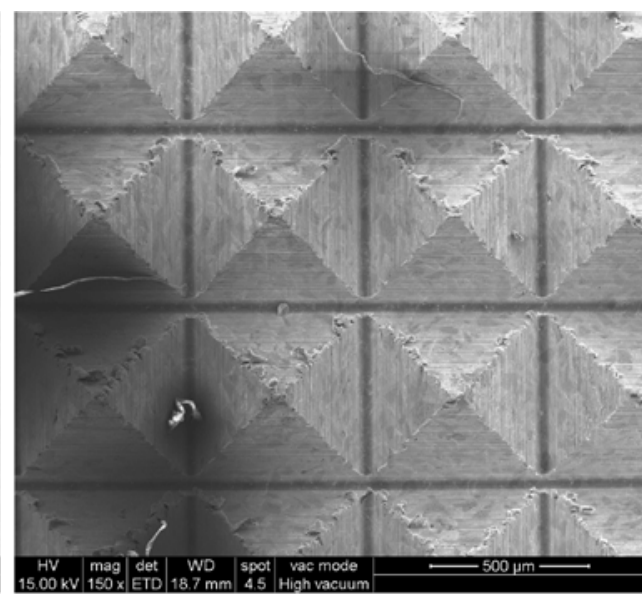

(b) Micro-pyramid array structure

Fig. 6. The ground surface topography of SiC reinforced Al composites after micro-grinding: (a) micro-groove array structure and (b) micro-pyramid array structure. 
Fig. 6 presents that the ground surface topography of $\mathrm{SiC}$ reinforced $\mathrm{Al}\left(\mathrm{Al} / \mathrm{SiC}_{\mathrm{p}}\right)$ composites after micro-grinding using trued SD600 V-tip diamond grinding wheel. Compared with microcrystallite glass and reaction sintered SiC ceramics surfaces, the surface machining quality of $\mathrm{SiC}$ reinforced $\mathrm{Al}$ composites was worst. Besides, the breakage of micro-groove tip was very serious and there were many burrs at the edge of micro-pyramid. This is because the aluminum substrate contained SiC particles. The collision or brittle rupture extremely easily occurred in the grinding process of $\mathrm{Al} / \mathrm{SiC}_{\mathrm{p}}$ composites. Therefore, the machining of $\mathrm{Al} / \mathrm{SiC}_{\mathrm{p}}$ composites was very difficult.

\section{Conclusions}

The high efficient and precise V-tip truing of diamond grinding wheel was realized using dry ECD truing method. The pulse discharge parameters were optimized in the experiment of V-tip truing. The optimal pulse discharge parameters were open-circuit voltage $E$ of $5 \mathrm{~V}$, pulse frequency $f$ of $4000 \mathrm{~Hz}$ and duty cycle $d_{c}$ of $50 \%$. The sharp micro grain cutting edge on the wheel surface was formed after ECD truing. The least V-tip angle error and radius of trued SD600 V-tip diamond grinding wheel was $1.1^{\circ}$ and $33 \mu \mathrm{m}$, respectively. The trued V-tip diamond wheel can be employed to fabricate regular and smooth micro-groove and micro-pyramid array structures on the surfaces of hard and brittle materials such as microcrystallite glass ceramics and $\mathrm{Al} / \mathrm{SiC}_{\mathrm{p}}$ composites.

\section{Acknowledgments}

This project was supported by the China Postdoctoral Science Foundation [Grant No. 2016M602460], the Opening Project of the National Engineering Search Center of Near-net-shape Forming for Metallic Materials [Grant No. 2015001], the Fundamental Research Funds for the Central Universities [Grant No. 2015ZM105], the Science and Technology Planning Project of Guangdong Province [Grant Nos. 2016A040403043 and 2017A010102003] and the Youth Projects for Creative Talents of Educational Commission of Guangdong Province [Grant No. 2015KQNCX009].

\section{References}

[1] K. Egashira, S. Hosono, S. Takemoto, Y. Masao, Fabrication and cutting performance of cemented tungsten carbide micro-cutting tools, Precis. Eng. 35 (2011) 547-553.

[2] Q. L. Zhao, B. Guo, Ultraprecision Grinding Technology of Microstructured Optical Functional Molds, J. Mech. Eng. 47 (2011) 177-185.

[3] Y. J. Lu, J. Xie, X. H. Si, Study on micro-topographical removals of diamond grain and metal bond in dry electro-contact discharge dressing of coarse diamond grinding wheel, Int. J. Mach. Tools Manuf. 88 (2015) 118-130.

[4] J. Xie, H. F. Xie, M. J. Luo, T. W. Tan, P. Li, Dry electro-contact discharge mutual-wear truing of micro diamond wheel V-tip for precision micro-grinding, Int. J. Mach. Tools Manuf. 60 (2012) 44-51. 